\title{
Author Index Vol. 11, 1989
}

Amason, B.G.W. 118 Avellana-Adalid, V. 397, 414

Barg,J. 428 Bass,T. 52 Baumann, N. 132 Bixby.J.L. 332 Black, J.A. 99 Biaaier.D. 397,414 Bock, E. 149 Buettner, H.M. 361 Bunge,M.B. 348 Bunge,R.P. 348 Biirgisser, P. 179 Burrous,B.A. 313

Cammer.W. 90 Carbonetto, S. 225 Caron,M. 397,414 Chiquet,M. 266 Clos,J. 188 Collins, V.P. 174 Colman,D.R. 377

Dean,A.C. 348 Doinel, C. 397 Dollison, A.M. 205

Eberhart, R. 188

Flier, L.A. 300 Friedman, B. 99

Gansmuller, A. 132 Ghandour, S. 188 Gombos, G. 188 Goto.N. 212 Gout,0. 132 Guan,Y.L. 1 Gumpel, M. 132 
Hall,D.E. 332 Heaton,M.B. 391 Hirano.A. 112 Hlibczuk,V. 205 Hockfield,S. 99 Honegger, P. 30

Ignacio, V. 174 Ignatius, M.J. 332 Inouye, H. 81

Jacque, CM. 174 Joubert,R. 397,414

Kanfer.J.N. 26 Kirschner, D.A. 81 Kleinman, H.K. 313 Kleitman,N. 348 Kuchler,S. 397,414

Letourneau, P.C. 248 Linnemann, D. 149 Lubetzki, C. 132 Ludwin.S.K. 140 Luo,Z.B. 1

Margolis, R.K. 276 Margolis, R.U. 276 Martin-Martinelli, E. 11 Matthew, W.D. 289 Matthieu, J.-M. 179 McCartney, life. 26 McMahan,UJ. 227 Monnet-Tschudi, F. 30

Nara,T. 212 Nelson, D. J. 118 Neugebauer, K.M. 332 Nguyen-Legros, J. 11 
Pech,I.V. 248 Pittman,R.N. 41,361 Pranzatelli, M.R. 205

Ransom, B.R. 99 Reichardt, L.F. 332 Rogers, S.L. 248

Salzer.J.L. 377 Sandrock, A.W. 289 Sephel,G.C. 313 Simantov.R. 428 Simon, A. 11 Soliven,B. 118 Suard,I.M. 174 Suzuki, K. 65 Szuchet, S. 118

Tansey, F.A. 90 Tomaselli, K.J. 332 Turner, D.C. 300 Turtle, R. 289

Uzman,B.G. 65

Vigny,A. 11 Villegas, G.M. 65 Vincendon,G. 188,397,414 Volpe,J.J. 52

Wallace, B.G. 227 Waxman,S.G. 99 Williams, A.G. 41

Yamaguchi.K. 212 Yew.D.T. 1

Zanetta,J.P. 397,414 Zheng, D.R. 1 